\title{
SIMPATÍA, RESENTIMIENTO Y PERDÓN: UN ANÁLISIS DEL ROL DEL RESENTIMIENTO EN LA TMS DE ADAM SMITH
}

\author{
JEYver Rodríguez Baños* \\ doi:10.11144/Javeriana.uph34-68.srps
}

\begin{abstract}
RESUMEN
El artículo analiza el papel del resentimiento en la Teoría de los sentimientos morales de Adam Smith y su conexión con el proceso de la simpatía mutua por medio del cual el "espectador imparcial" asume plenamente el resentimiento de la víctima, al considerar que su pasión se rige por los principios de la propiedad y la justicia. Se sostiene que el resentimiento no solo cumple un rol central en la teoría del castigo de Adam Smith, en la medida en que permite retribuir, disuadir y rehabilitar al victimario sino que, además, aporta a la discusión contemporánea sobre el perdón y la reconciliación, pues convoca la posibilidad de superar el resentimiento y restablecer las relaciones sociales entre el agresor y la víctima.
\end{abstract}

Palabras clave: Adam Smith; resentimiento; indignación; simpatía; perdón*

* Pontificia Universidad Católica de Chile, Santiago de Chile, Chile

Correo electrónico: jrodriguez12@uc.cl

Para citar este artículo: Rodríguez Baños, J. (2017). Simpatía, resentimiento y perdón: un análisis del rol del resentimiento en la TMS de Adam Smith. Universitas Philosophica, 34(68), pp. 197-218. ISSN 0120-5323, ISSN en línea 2346-2426. doi:10.11144/Javeriana.uph34-68.srps

Este artículo se origina en los resultados del Seminario: Ética, politica y mercados: Adam Smith y sus proyecciones contemporáneas, dirigido por la Dra. María Alejandra Carrasco a quien agradezco las horas de diálogo constructivo y su generosidad al discutir los argumentos principales del presente trabajo. 


\title{
SYMPATHY, RESENTMENT AND FORGIVENESS: AN ANAYSIS OF RESENTMENT ROLE IN THE ADAM SMITH'S TMS
}

\author{
Jeyver Rodríguez BaÑos
}

\begin{abstract}
The article analyses the role of resentment in The Theory of Moral Sentiments and its connection with the process of mutual sympathy which the impartial spectator assumes fully the resentment of the victim, to consider that his passion is governed by the principles of property and justice. It is argued that the resentment not only fulfills a central role in the theory of punishment of Adam Smith, in that it allows you to remunerate, dissuade and rehabilitate the perpetrator, but it also contributes to the contemporary discussion about forgiveness and reconciliation, as it calls the possibility to overcome resentment and restore the social relationship between the aggressor and the victim.
\end{abstract}

Key words: Adam Smith; resentment; indignation; sympathy; forgiveness 


\section{Introducción}

En la The Theory of Moral Sentiments ${ }^{1}$, Adam Smith desarrolla los elementos centrales de lo que en la actualidad se conoce como su teoría del castigo. Smith argumenta en favor del resentimiento entendiéndolo como una pasión que "subyace a la virtud de la justicia" (Fleischacker, 2006, p. 30). El resentimiento abre paso a la "justa indignación" y convoca el castigo apropiado por el daño real y positivo del que ha sido objeto la persona afectada por la acción injusta. La argumentación principal del trabajo gira en torno al resentimiento entendido como una pasión que cobra realidad en la medida en que existe una interacción efectiva entre un agresor y una víctima capaz de resentir un daño real y positivo. Al respecto Fricke (2015) argumenta que pasiones como la ira y la venganza, "solo tienen sentido cuando los daños han sido causados por acciones intencionales de otras personas [es decir, cuando existe] un proceso comunicativo entre un agresor y su víctima" (p. 128).

El resentimiento está en el centro de la discusión filosófica contemporánea sobre el problema del perdón, el olvido y la reconciliación. En trabajos recientes sobre estos temas se argumenta que el resentimiento en Smith está más cerca de lo que algunos autores actualmente denominan como "odio retributivo" (Murphy, 1988, p. 109). En el curso del actual trabajo se sostiene que el resentimiento está vinculado no solo con el "odio retributivo" que lleva sancionar al victimario sino, especialmente, con la "justa indignación" que permite el desagravio de la víctima. Este artículo se centra en el proceso simpatético descrito por Smith analizando la interacción entre el "agente" y el "espectador imparcial". Mi tesis es que el proceso de la "simpatía mutua" puede aportar a la discusión contemporánea sobre el perdón y la reconciliación en la medida en que abre la posibilidad de superar el resentimiento y restablecer las relaciones sociales entre el agresor y la víctima. Se sostiene que el "resentimiento apropiado" o "generoso" debe estar acompañado por el self-command y regido por el sentido de la corrección (sense of propriety), bajo estas circunstancias el resentimiento es reconocido no solo por su valor "retributivo" o "punitivo" sino, especialmente, por su valor político pues

1 En adelante TMS. Las citas siguen el estilo canónico: parte, sesión, capítulo, parágrafo, y se realizan siguiendo la edición de D.D. Raphael y A.L. (1982), Macfie. 6th edition. Indianapolis: Liberty Fund, Inc. 
es el testimonio de una sociedad que todavía es capaz de manifestar su respeto y solidaridad hacia el sufrimiento de las víctimas.

\section{Moderar el resentimiento o el placer de la "mutua simpatía"}

Según SMith, el amor propio (self-love) es LA PASIÓn que más fervientemente impulsa al hombre a actuar de manera egoísta, buscando satisfacer su propio interés. Sin embargo, por contrapartida, existen otras pasiones y procesos que, por naturaleza, llevan a que el hombre pueda interesarse por el bienestar y la felicidad de los demás aún cuando esa felicidad no le reporte ningún beneficio salvo el disfrute de esa misma felicidad (TMS I.i.1. p. 9). La simpatía, de acuerdo con Smith, denota la capacidad de acompañar e incorporar "en el propio pecho" las pasiones de la otra persona (fellow-feeling) (TMS I.i.I.5. p. 10). Ahora bien, es por medio de la imaginación que logramos adoptar por completo las agonías y miserias de los que sufren. En algunas ocasiones, continúa Smith, la sola contemplación del sufrimiento real o imaginario de otra persona basta para que las pasiones puedan "transfundirse rápidamente de un individuo a otro" (TMS I.i.I.6. p. 11). Sin embargo, este principio no es universalmente válido, pues sabemos que frente a algunas pasiones lo que experimentamos más intensamente, como espectadores, es un sentimiento de repulsión y antipatía. Es el caso del resentimiento, la ira, el deseo de venganza y otras "pasiones antisociales". Así, cuando vemos a un hombre cegado por la rabia y la desesperación, que está a punto de descargar su cólera y resentimiento hacia otro, lo primero que se nos pasa por la mente es el deseo de ayudar a aquel que va a sufrir el daño.

De lo anterior deriva Smith un principio fundamental: "la naturaleza nos enseña a sentir más aversión que simpatía frente al resentimiento hasta tanto no nos informemos de las causas que lo suscitaron" (TMS I.i.I.8. p. 11). Por ahora, continúa, lo único que podemos hacer es "tomar partido en su contra”. De lo anterior se deduce que solo podemos simpatizar con el agente en la medida en que estemos informados de la situación que originó la pasión. De esta manera podremos evaluar si la manifestación de su pasión es adecuada y apropiada a las causas que la originaron. A partir de lo anterior cabe plantearse: ¿Cuándo y bajo qué circunstancias consideramos como apropiado el resentimiento de la víctima? Al respecto Smith afirma: 
Cuando las pasiones originales de la persona principalmente afectada están en perfecta concordancia con las emociones simpatizadoras del espectador, necesariamente le parecen a este último justas y apropiadas, y en armonía a sus objetos respectivos [...] El hombre que resiente el daño que me ha sido causado y observa que mi enojo (resent) es igual al suyo, necesariamente aprobará mi resentimiento. (TMS I.i.3.1.p. 16)

Cabe señalar que la aprobación o desaprobación del resentimiento depende de la concordancia y propiedad entre los sentimientos de la víctima y las emociones simpatizadoras del espectador. Después, este se convierte en el "estándar de imparcialidad" que permite definir el juicio normativo relacionado con el castigo (Brooks, 2012, p. 282). Conviene destacar que el resentimiento que defiende Smith no es cualquier tipo de resentimiento sino algo que llamaré un "resentimiento apropiado", entendido como una pasión activa que nos incita a controlar y restringir (self-command) una de nuestras pasiones más acuciantes. Moderar el resentimiento no siempre resulta fácil pero es lo único y lo mejor que podemos hacer si queremos que los demás simpaticen con nuestro sufrimiento. En el caso del resentimiento, la simpatía del espectador se divide entre la persona que siente la pena y la persona que es objetivo de ese resentimiento. Por eso, agrega Smith, antes de que el resentimiento pueda resultar "gallardo" y "grato" desde el punto de vista del espectador imparcial, este debe ser "reducido por debajo del límite" de propiedad en que habitualmente se expresan las demás pasiones (TMS I.ii.3.1. p. 34).

Adicionalmente, el resentimiento no solo debe ser moderado sino también "adecuado y apropiado a la situación". El espectador imparcial, como argumenta Carrasco (2014), "no se ubica fuera de la situación sino que participa en ella, interactúa (de manera virtual o real con los agentes) y es personalmente afectado con la situación. El espectador en segunda persona se relaciona con los agentes; "entra" al mundo y juzga desde dentro" (pp. 64-65). El espectador imparcial en segunda persona, de acuerdo con Carrasco, debe evaluar la situación entera "desde dentro", tanto desde el punto de vista de la persona que sufre la afrenta como desde el punto de vista de la persona que es objetivo del resentimiento. En el primer caso, si la persona que sufre la afrenta se somete a su agresor dejando este le trate como a un inferior (TMS I.i.5.5. p. 35), aquel hombre se torna "despreciable e insensible" a los ojos del espectador, pues todo hombre debe ser tratado con el debido respeto y cuidado que exige su persona en tanto que persona. Lo que 
se espera, en este caso, es que el sufriente haga algo para repeler el daño y restituir su propia dignidad, es decir, que la injuria sea "resentida por la propia persona que la padece" (TMS I.i.5.7. p. 35). En el segundo caso, cuando la emoción se expresa de manera inapropiada, el espectador no puede aprobar la conducta de la persona que siente el resentimiento, pues lo que observa le lleva a evaluar el caso poniéndose del lado de la persona que es objetivo del resentimiento (TMS I.ii.3.4. p. 35).

En coherencia con lo anterior, quiero resaltar que el resentimiento por una acción injusta y arbitraria no puede dar cabida a una cadena de actuaciones injustas y arbitrarias. Por el contrario, el desarrollo de la conciencia moral implica que la persona que ha sido agraviada y deshonrada puede controlar (self-command) y moderar (restraint) sus pasiones y sufrimientos en conformidad con "las emociones restringidas y corregidas" que prescribe y aprueba el espectador imparcial, denominado por Smith como el "hombre interior (the man within) dentro del pecho, el alto juez y arbitro de su conducta” (TMS III.2.32. p. 130).

Smith destaca que el resentimiento nos impulsa a rechazar el perjuicio que nos intentan infligir y a buscar la retaliación del daño que ya nos han causado, para que el agresor se vea forzado a arrepentirse de su injustica (TMS II.ii.I.4. p. 79). "Justicia aquí ya no es solo propiedad de la acción respecto del espectador imparcial, esto es, de la ley, sino, fundamentalmente, castigo a las injurias, legítima retaliación, venganza y revancha, que se ejerce contra quien injuria a otro en su vida, propiedad o contrato" (Gutiérrez, 1998, p. 64). Las "más sagradas leyes de la justicia”, de acuerdo con Smith, son aquellas cuyo quebrantamiento demanda de la venganza y el castigo. Primero, están las que protegen la vida e integridad del prójimo; luego, las que defienden su propiedad y posesiones y, finalmente, las que protegen los derechos personales y los contratos (TMS II.ii.2.2. p. 84). Como indica Fricke (2011), si los miembros de una sociedad no actuaran de hecho en concordancia con estas leyes, "ellos nunca podían conseguir ningún consenso sobre los estándares del comportamiento apropiado que se podrían considerar como más objetivos, justificados o de mayor autoridad moral" (p. 46).

Por otra parte, conviene resaltar que el resentimiento, tal y como lo comprende Smith, no puede justificar cualquier forma de brutalidad, pues todas estas pasiones deben regirse por el self-command a cuyo arbitrio llegan a "ser 
moderadas por un sentido de misericordia y controladas por un imperativo del deber" (Fassin, 2013, p. 172). Al respecto, Smith señala:

Antes de adoptar el resentimiento del sufriente debemos reprobar los motivos del agente y sentir que nuestro corazón renuncia a toda simpatía con los afectos que influyeron sobre su proceder. Si resulta que no hay impropiedad en estos, entonces por más nefasta que sea la tendencia de la acción que de ellos se deriva en contra de aquellos hacia quienes se orienta, no parece merecer castigo o ser el objeto adecuado de ningún resentimiento. (TMS II.i.4.4. p. 74)

Como indicaba al inicio de este trabajo, el estándar de la imparcialidad, "es usado para determinar si un acto dado merece castigo. Por lo tanto, no vamos a centrarnos en nuestras propias sentencias, pero el juez en su lugar desde la perspectiva de un espectador imparcial debe evaluar si la solicitan. Para Smith, la satisfacción de este estándar de imparcialidad es una garantía de justicia imparcial" (Brooks, 2012. p. 282). La simpatía con el resentimiento, de acuerdo con Smith, depende de los siguientes principios: primero, que cuando aprobamos los motivos del agente no es posible simpatizar con el resentimiento de la persona agraviada, pues este se constituye en el objetivo aprobado y apropiado del castigo y, segundo, que para poder simpatizar con el resentimiento de la persona agraviada es necesario que antes se desapruebe los motivos que influyeron en la conducta del agente. Si los motivos del agente son inapropiados e incorrectos no es posible sostener ningún tipo de solidaridad con él (TMS II.i.3.2. p. 72). En palabras de Smith:

Pero cuando al perjuicio de la acción se une la impropiedad del afecto del que procede, cuando nuestro corazón rechaza con aborrecimiento toda solidaridad con los impulsos del agente, entonces simpatizamos total y entusiastamente con la ira del paciente. Tales acciones parecer entonces merecer y, si se me permite decirlo, claman a voces por un escarmiento proporcional; y entonces adoptamos por entero y en consecuencia aprobamos la animadversión (resentment) que compele a infligirlo. El ofensor parece entonces el objeto adecuado de la pena, cuando simpatizamos así totalmente, y por consiguiente aprobamos el sentimiento que impulsa a sancionar. (TMS II.i.4.4. p. 74)

En el segundo caso se da el placer de la "mutua simpatía" (TMS I.i.2.1. p. 13), entendida como la plena concordancia y armonía entre los sentimientos del 
agente y el espectador. La injusticia, en consecuencia, "consiste en la conducta inapropiada (motivada por motivos inapropiados) cuya respuesta apropiada es un sentimiento reactivo de retaliación y venganza que aparece como resentimiento y motiva a desafiar, resistir o castigar la conducta enérgicamente" (Darwall, 1999, p.142).

En resumen, el resentimiento puede considerarse como apropiado a sus objetivos cuando: (i) se ha dado un proceso simpatético por medio del cual, el espectador imparcial acoge la situación entera de la víctima y puede hacerla suya; (ii) cuando el resentimiento de la víctima es proporcional a las circunstancias, esto es, cuando no excede el límite de lo apropiado y adecuado; (iii) cuando se da una perfecta consonancia y armonía entre las emociones de la víctima y las emociones simpatizadoras del espectador imparcial: sin esta plena identificación no es posible determinar el resentimiento de la víctima como apropiado por más justas que parezcan las causas que lo originaron, y (iv) cuando la persona puede situarse en la posición de la segunda persona, la cual le permite evaluar su propia situación desde la perspectiva del espectador imparcial.

Respecto del proceso simpatético, por medio del cual logramos simpatizar con el sufrimiento de las personas que han sido objeto de un daño real y positivo, Smith indica: "Pero si usted no tiene conmiseración (fellow-feeling) por las adversidades que me acosan, o no la siente en la proporción a la angustia que me perturba; o si no bulle usted de indignación por el mal que sufro, o no lo hace en la proporción al rencor (resentment) que me agita, entonces ya no podemos conversar sobre esas cuestiones" (TMS I.I.4.6. p. 21). En esta cita, Smith introduce un elemento decisivo relacionado con la indignación que siente la víctima al constatar que la otra persona no tiene ningún tipo de solidaridad (fellow-feeling) hacia sus angustias y adversidades. Así, si su compañero siente "demasiado poco" le despreciará como insensible y despiadado, con lo cual se tornan "recíprocamente intolerables". Esta incapacidad de solidarizarse con el sufrimiento, de acuerdo con Smith, pone en riesgo el orden y armonía de la sociedad civil. Para hallar una correspondencia apropiada entre los sentimientos del espectador y los de la víctima, el primero debe, ante todo, hacer el máximo esfuerzo de "ponerse en el lugar del otro" y tratar de asumir "hasta los últimos detalles" la situación de la víctima (TMS I.i.4.6. p. 21). La víctima, a su vez, debe esforzarse por rebajar al mínimo la pasión que, en su interior, late imperiosamente y reclama la mayor 
atención. Así, si la víctima logra ejercer el gobierno (self-government) sobre sus propias pasiones se convierte en un ser admirable y respetable.

Es el caso de muchas de las víctimas del conflicto armado colombiano, quienes han logrado superar su sufrimiento en "una auténtica experiencia del perdón que acontece en el límite siempre frágil y borroso de la propia subjetividad que está impelida a reclamar justicia, al tiempo que a rehacerse constantemente, incluso emergiendo de las cenizas que dejan el horror de la muerte" (Prada-Londoño, 2010, p. 87). Un dolor de esa naturaleza no reclama únicamente nuestra más genuina solidaridad sino que, además, despierta nuestra más profunda admiración y respeto hacia el sufrimiento de las víctimas.

Por otra parte, argumenta Smith, no hay nada más detestable y digno de reproche que:

La insolencia y la brutalidad de la ira, cuando le damos rienda suelta sin freno ni control. Pero admiramos ese resentimiento noble y generoso que responde a las mayores injurias no con la cólera que puede animar el pecho del agraviado, sino con la indignación a que naturalmente dan lugar en el espectador imparcial [...] ni desea infligir un escarmiento mayor que el que cualquier persona indiferente aprobaría de buen gusto. (TMS I.i.5.4. p. 24)

Al referirse al "resentimiento noble y generoso", Smith no se está refiriendo, como a primera vista podría entenderse, a que la víctima deba fingir que no está sufriendo, pues ello podría transformarse en odio enfermizo hacia el victimario. El "resentimiento generoso" está relacionado con la “justa indignación”, por la cual la víctima logra tener el gobierno (self-government) de sus propias pasiones hasta el punto de propiedad en que pueda asumirla el espectador imparcial (TMS VI.iii.9. p. 240). El resentimiento generoso, de acuerdo con Smith, debe estar acompañado por el self-command y regido por el sentido de la corrección (sense of propriety), esto es, por la debida observación de los sentimientos del supuesto espectador imparcial (TMS 6. Concl.3). Al respecto argumenta Carrasco (2004):

Solo esta última "restricción” es una manifestación de dominio de sí mismo (self-command). La inadecuación de sentimientos en una situación dada significa que nadie simpatiza con nosotros y no adquirimos ningún placer, eso nos lleva, entonces, a acomodarlos apropiadamente. Este aprendizaje no tiene que ser consciente (en el sentido que es el aprendizaje teórico), pero es claramente una especie de ajuste reflexivo de nuestros sentimientos espontáneos 
que es dirigido por una idea de que una mejor actitud causa la aprobación de nuestros compañeros. Así, el dominio de sí mismo (self-command) en la teoría de Smith incluye alguna clase de la deliberación. (pp.102-103)

La formación del self-command, como argumenta Carrasco (2014 p. 64), y su manifestación en la restricción (restraint), que imponemos a nuestros sentimientos cuando notamos que los demás son incapaces de simpatizar con nosotros, no acontece por la reflexión teórica sino por cierto tipo de ajuste reflexivo que permite adecuar nuestros sentimientos y moderar la expresión de nuestras pasiones, teniendo en cuenta el principio de la propiedad y la justicia. En síntesis: Smith explica el proceso simpatético que lleva al juicio moral a partir de la relación que se establece entre un "agente" y un "espectador imparcial”. Smith, a diferencia de Hutcheson y Hume, sitúa al espectador imparcial dentro de la "situación juzgada”, es decir, en una relación interactiva y dinámica con el agente.

El espectador no tiene acceso a la mente del agente pero sí puede informarse acerca de los motivos que impulsan su conducta accediendo a los observables del agente: sus circunstancias y su acción (Stevens, 2011, p. 8). Ello exige ponerse uno mismo en la situación del agente y evaluar desde esa perspectiva los motivos de la acción. Si podemos simpatizar con los motivos del agente, aprobamos la acción por considerarla apropiada y adecuada. En caso contrario, si no podemos asumir "el caso" o la "situación" entera del agente tampoco podemos simpatizar con él, entonces desaprobamos su acción por considerarla impropia e inadecuada con los sentimientos del espectador (TMS II.i.4.1. p. 73).

\subsection{TEORÍA DEL CASTIGO: JUSTICIA Y RESENTIMIENTO}

EN la PARTE II DE LA TMS, Adam Smith propone dos principios en los que se fundamenta su teoría del castigo: "Para nosotros, entonces la acción que merezca recompensa deberá ser la que parece el objeto adecuado y apropiado de la gratitud y por otro lado, la que merezca castigo deberá ser la que parece el objeto adecuado y aprobado del resentimiento" (TMS II.I.1.3. p. 68). Y agrega: "Recompensar es retribuir, remunerar, retornar el bien por el bien recibido. Castigar también es retribuir, remunerar, aunque de un modo diferente: es retornar el mal por el mal que se ha hecho" (TMS II.I.1.4. p. 68).

Posteriormente, Smith explica que solo estos dos sentimientos, la gratitud y el resentimiento, son los que, más intensamente, nos impulsan a desear su plena 
gratificación. En el caso de la gratitud, dice el autor, estaremos cargados con la deuda de los pasados servicios del benefactor "hasta que no podamos ser los instrumentos de promoción de su felicidad” (TMS II.I.1.5, p. 68). Paralelamente, nuestro resentimiento no quedará saciado a menos que "el culpable sufra él mismo y se duela por ese mal concreto que hemos padecido por causa suya". [El culpable] "debe arrepentirse y lamentar esa acción en particular, de forma que los demás, por el temor de un castigo similar queden aterrorizados de ser culpables de un delito parecido" (TMS II.ii.1.10. p. 69. La cursiva es mía). El castigo cumple una función doble: por una parte, debe brindar los medios apropiados para corregir y rehabilitar al victimario y, por otra, debe ser ejemplarizante para impedir que los demás miembros de la comunidad política violen las "sagradas leyes de la justicia”. Más adelante Smith insiste en el hecho de que la consecuencia natural del resentimiento es "la venganza y el castigo" (TMS II.ii.2.3. p. 84).

El resentimiento vincula con el desagravio de la víctima en la medida en que permite establecer el castigo apropiado para evitar que el mal hecho se vuelva a repetir. Para poner fin a la injusticia debe efectuarse el reconocimiento mutuo, tanto por parte de la víctima como por parte del victimario, del mal concreto y real que se ha causado en la otra persona. Cuando el victimario, mediante la simpatía, logra verse con los ojos del espectador (juez) llega a reconocer a la víctima como sujeto, como un ser con la misma dignidad que todos los demás en el marco de la sociedad civil. La justicia debe hacer que le agresor sea consciente de que sus padecimientos se deben a su conducta pasada por ese daño particular y concreto que le ocasionó a una persona en un circunstancias particulares. La sanción debe llevar a que el victimario lamente y se arrepienta de su conducta anterior sensibilizándose y aceptando que la persona a quien lesionó no merecía dicho trato. Finalmente, y lo más importante, el principal fin del desagravio, de acuerdo con Smith, es hacer que el agresor "recupere un sentido más justo de lo que se debe a los demás” (TMS II.iii.1.5. pp. 95-96). El daño causado por el victimario despierta el sentimiento de indignación y el deseo de venganza en la víctima. En estos casos, la víctima siente un profundo odio y antipatía por el victimario. Al evaluar el daño que el victimario le ha causado, la víctima constata que el agresor ha actuado sin ningún tipo de respeto por su persona, en tanto partícipe de la comunidad política. 
Las narrativas de las víctimas en Colombia ayudan a comprender situaciones en las que los agresores armados instituían castigos severos en quienes colaboraban con aquellas personas a quienes ellos habían declarado arbitrariamente como sus enemigos. A algunas víctimas les imponían castigos como el "encierro voluntario" o la expulsión del territorio con el fin de sembrar el terror y minar la esperanza entre los demás miembros de la comunidad. Todo lo anterior corrobora la existencia de un sistema coercitivo y reaccionario que haciéndose pasar por "la ley" imponía en el ser social de las personas injuriadas una serie de desventajas conducentes a menoscabar la identidad de la víctima relegándola de lo social. En una dirección similar argumenta Frankfurt (1997): “Tratar a las personas con respeto impide asignarles ventajas o desventajas, excepto sobre la base de consideraciones sobre las diferencias relevantes entre ellos. Así, implica la imparcialidad y la evitación de la arbitrariedad" (p. 6). El victimario, mediante el quebrantamiento de las leyes de la justicia, instituye un campo de regulaciones basadas en el miedo y la arbitrariedad las cuales empiezan a fungir como la nueva ley.

Así, las relaciones sociales se pervierten a tal punto que los demás miembros de la comunidad se ven obligados a cooperar con el crimen, convirtiéndose en cómplices y espectadores indiferentes del abuso y el atropello. En síntesis, lo que más despierta nuestra indignación es el notar que el victimario ha obrado sin ningún tipo de consideración por otras personas que son como él. Con la acción injusta, el agresor hace un daño real y concreto en una persona que no merecía ser tratada de ese modo, y además, destruye las relaciones sociales de confianza y respeto que hacen posible pensarnos como actores sociales desde la perspectiva del nosotros. Siguiendo a Fricke (2015):

$\mathrm{Al}$ obrar el mal, el agresor no solo ha dañado a su víctima, sino que también ha violado las normas que gobiernan las relaciones sociales constitutivas de su comunidad. Tal violación representa una clase particular de daño psíquico no solo para la víctima, sino también para el agresor: obrar mal incluye tanto un acto de dañar a otro (other damage) como un acto de dañarse a sí mismo (self-damage). (p. 128)

Fricke argumenta que el daño ocasionado por el victimario altera las relaciones sociales de la comunidad y, en última instancia, marca un hito temporal entre las relaciones sociales entre el agresor y la víctima. 
Para restablecer la confianza mutua, las relaciones sociales entre el agresor y su víctima tienen que ser reparadas o redefinidas. Su futuro común puede tomar la forma de una relación de renovada cercanía o de una más o menos remota coexistencia. El proceso del perdón, si es exitoso, allana el camino para que el agresor, su víctima, y los otros miembros de su respectiva comunidad, restablezcan la confianza mutua. (Fricke, 2015, p. 129)

El proceso del perdón, desde la perspectiva del presente trabajo, brinda la posibilidad de restaurar no solo los lazos de solidaridad entre las personas y la comunidad social sino que, además, permiten la adhesión y el empoderamiento político y social de la víctima hacia la construcción de nuevos proyectos futuros. El perdón inaugura un nuevo comienzo, comienzo siempre doloroso y no exento de retrocesos, en el que es posible reescribir la propia historia y participar activamente en la comprensión y reparación colectiva del sufrimiento.

\subsection{SUPERAR EL RESENTIMIENTO}

Como ejemplo de lo ANTERIOR, pueden citarse las narrativas de la Fundación Victimas visibles y de la Ruta Pacifica de Mujeres donde se describen no solo las violaciones sistemáticas de derechos humanos, como esclavitud sexual, ejecuciones extrajudiciales y el exterminio de comunidades indígenas a manos de los diversos actores armados involucrados en el conflicto colombiano sino, además, los procesos de empoderamiento político de diversas comunidades que han logrado rehacer sus vidas y coadyuvar en la construcción de escenarios sociales de paz, verdad, justicia y reparación desde la perspectiva de los sobrevivientes. ${ }^{2}$ El resentimiento, como se ha venido argumentando en el presente trabajo, permite rehabilitar al victimario en la medida en que llama a imponer un castigo apropiado y nos impone el deber moral de hacer memoria de lo acaecido. Como afirma Fassin (2013):

2 La participación activa de la Ruta Pacífica de Mujeres ha sido pieza clave en el trabajo de las comisiones de verdad, cuya labor exige crear las condiciones de posibilidad para que la verdad de los hechos pueda salir a la luz pública como paso previo para el establecimiento de mínimos de justicia para las víctimas, quienes muchas veces se sienten no solo abatidas, sino desorientadas y confundidas por el lento funcionamiento de la justicia ordinaria. Para un análisis más detallado del aporte de las Mujeres a la construcción de mínimos de justicia en Colombia remito al valioso trabajo de Comins-Mingol (2015), De víctimas a sobrevivientes: la fuerza poiética y resiliente del cuidar. Un amplio análisis de las narrativas y experiencias pacíficas puede hallarse en el sitio web de la Ruta Pacifica de Mujeres: http://www.rutapacifica.org.co/ 
El resentimiento es una legítima pasión que debe ser domesticada por los principios que regulan la retribución. Pone a los seres humanos en riesgo de parecerse a los animales cuando se conduce a la simple venganza, pero puede ser disciplinado mientras un sentido de justicia prevalece, y por lo tanto, puede considerarse como un componente indispensable de legítima defensa en la vida social. (p. 251)

En el caso colombiano, uno de los objetivos básicos de la justicia transicional es hacer que "los individuos y grupos de una sociedad dejen a un lado su rígida insistencia en mantener sus papeles del pasado y accedan a una identidad común como sobrevivientes que forman parte de un sola comunidad política y moral que deben construir juntos" (Minow, Crocker \& Mani, 2011, p. 188). La reparación debe dar a las personas que han sido despojadas de su territorio y su dignidad la posibilidad de empoderarse y constituirse social y culturalmente en el horizonte pleno de la justicia reparativa, la cual exige que se restituyan no solo materialmente sino que se realice un desagravio moral por los procesos de victimización de los que fueron objeto.

La pregunta que surge de lo anterior es la siguiente: ¿En qué medida el proceso simpatético que se ha venido analizando puede contribuir a transformar el resentimiento desbordado, que no da ocasión a la superación del odio y el deseo de venganza, en un resentimiento apropiado el cual es asumido enteramente por el espectador imparcial?

$\mathrm{Al}$ respecto, argumenta Smith: "al igual que las otras pasiones de la naturaleza humana, parecen apropiados y son aprobados cuando en el corazón de cada espectador imparcial simpatiza enteramente con ellos, cuando cada testigo indiferente (by-stander) los asume por completo y los acompaña" (TMS II.i.2.2. p. 69). La simpatía, de acuerdo con Smith, permite solidarizarnos afectivamente con el resentimiento de la persona concernida, cuando cualquier testigo u observador indiferente logra asumir la situación entera de la víctima. En este caso, el filósofo agrega: "Así como nuestro corazón adopta su aflicción y palpita con ella, resulta animado con ese espíritu con el cual procura apartar o destruir la causa de la misma" (TMS II.i.2.5. p. 70). De esta manera, explica, los sentimientos pasivos e indolentes con los que acompañamos a la víctima ("The indolent and passive fellow-feeling') dan paso a sentimientos más vigorosos y activos, los cuales permiten una identificación plena con el resentimiento de la víctima: "cuando vemos a 
una persona oprimida o lesionada por otra, la simpatía que sentimos por la desgracia de la ofendida sirve para animar nuestra solidaridad (fellow-feeling) con su resentimiento hacia la ofensora” (TMS II.i.2.5. p. 70). Estamos dispuestos a socorrerla, afirma Smith, siempre y cuando "se esfuerce por defenderse e incluso, en cierto grado, por vengarse".

Cuando la persona concernida ha perdido la vida a manos de su victimario, nuestra solidaridad hacia el muerto y nuestro deseo natural de venganza se torna aún más vivo y perentorio: "sentimos el resentimiento que imaginamos sentiría él [el muerto] y que sin duda sentiría si en su cuerpo frío y exánime latiese alguna conciencia de lo que trascurre sobre la tierra. Pensamos que su sangre clama por venganza. Hasta las cenizas de los muertos parecen perturbadas ante la idea de que sus padecimientos no serán vengados" (TMS II.1.2.5. p. 71). Este pasaje sirve para precisar dos ideas centrales en mi argumentación. En primer lugar, que la imaginación simpatética, descrita por Smith, es un mecanismo de respuesta moral por el cual podemos sentir el resentimiento no solo de las víctimas en su calidad de sobrevivientes sino, incluso, el de los muertos quienes por su propia naturaleza son incapaces de reclamar justicia ${ }^{3}$. El resentimiento se entiende como una legítima capacidad de reacción moral frente un daño individual y concreto que se vincula con el respeto debido al sufrimiento de las víctimas, incluso cuando estas ya no puedan exigir por sí mismas la reparación a sus males. El resentimiento apropiado y la justa indignación tienen no solo un valor retributivo que impulsa a sancionar sino, particularmente, un valor político, pues es el testimonio de una comunidad moral que todavía es capaz de desaprobar el mal y no permanecer impasible e indiferente ante el crimen y la violencia, como afirma López (2013):

No se puede permanecer indiferente ante la vejación de la que se es objeto o ante la injusticia que se tiene delante. La actitud pasiva de quienes han sido víctimas y la actitud indiferente de quienes son incapaces de solidarizarse con estas solo sirven para que la violencia se prolongue en el tiempo gracias a la

3 Smith aclara que existen casos peculiares como cuando el individuo injuriado muere en una pelea: el espectador puede simpatizar con la víctima imaginando aquello que "en verdad" sentiría el muerto si aún pudiera resentir la injuria. Se trata de una emoción que la persona agraviada "ya no puede sentir" y que, sin embargo, nosotros sentimos gracias a una "simpatía ilusoria" (illusive sympathy) con la víctima (II.i.2.4. p. 70). Vale la pena resaltar que "esa simpatía ilusoria es particularmente diferente de la simpatía genuina o no ilusoria, es decir, la simpatía donde hay correspondencia entre los sentimientos del simpatizante y la persona con la que se simpatiza" (Nanay, 2010, pp. 95-96). 
ausencia de la justicia. La memoria revela entonces su carácter profético al mostrarse como referente para que las comunidades morales y las sociedades en las que estas se inscriben superen la impunidad y la indiferencia. (p. 93)

Mi segundo argumento se funda en la siguiente cita de Smith: "Y al menos en lo que hace a estos crímenes [el asesinato], los más espantosos de todos, la naturaleza, anticipándose a toda deliberación sobre la utilidad del castigo, ha impreso de esa forma en el corazón del humano, con los caracteres más firmes e indelebles, una aprobación instintiva e inmediata de la sagrada ley de la retaliación” (TMS II.i.3.5. p.71). Smith, en contraposición a Hobbes, Hutcheson y Hume, argumenta que el castigo racional surge no por su utilidad pública sino por una "aprobación instintiva a la sagrada y necesaria ley de la retaliación". El resentimiento en Smith, como argumenta Stanlley (2012), "no es una receta para la irracionalidad y la venganza sino un sentimiento complejo y activo que impulsa a evitar el daño que nos pueden ocasionar y a exigir la reparación por ese mal concreto y particular que nos han ocasionado" (p. 71). El castigo debe ser apropiado a la acción injusta y debe brindar los medios para que el victimario tome conciencia de la falta cometida y se arrepienta de su conducta.

En el tránsito al posconflicto en Colombia, la justicia transicional debe brindar las condiciones para que el agresor se arrepienta y reconozca el mal que ha hecho y, de ser posible, que haga lo que este a su alcance para reparar o remediar el daño causado. Reconocer a las víctimas en su calidad de sobrevivientes y ayudar a evitar que el mal causado se vuelva a repetir es un imperativo ético al cual no se debe renunciar. Pero antes de que esto ocurra, los victimarios deben reconocer que los motivos que en el pasado los impulsaron a actuar sin misericordia eran injustos y arbitrarios. Los agresores deben desaprobar su conducta anterior como paso ineludible para solidarizarse con el sufrimiento de las víctimas. Todo esto corresponde al proceso de la simpatía gracias al cual el victimario desaprueba su conducta pasada y los motivos que le llevaron a cometer el crimen. El victimario, por la imaginación simpatética, debe ponerse en el lugar de la víctima y reconocer que la otra persona "no debía ser tratada de esa manera" y que lo que hizo fue inapropiado y digno de castigo (TMS II.iii.1.5. p. 95-96).

El resentimiento, desde esta perspectiva, se entiende como un sentimiento que nos incita tanto a repeler el daño injusto y, particularmente, a exigir la reparación y el desagravio por el daño y sufrimiento de la víctima: "Todo esto 
significa que el resentimiento no es una mera respuesta a la experiencia de ser lastimado. Resentimos los perjuicios que nos hacen solo cuando lo vemos hechos por un agente que actúa guiado por motivos impropios. Para juzgar si el motivo del acto era bueno o malo debemos ponernos imaginativamente en la posición del agente" (Stalley, 2012, p. 72).

La justa indignación implica que el espectador desaprueba los motivos que impulsaron la conducta del agente lo cual lleva a que se rompa toda solidaridad y simpatía entre el agresor y los demás miembros de la comunidad política. Así, se establece una clara relación entre resentimiento apropiado y justa indignación: el resentimiento compele a resistir el mal cuando el agente ha actuado por motivos impropios. En ese caso, el espectador asume plenamente la situación de la víctima y su justa indignación por el daño causado.

La indignación y el resentimiento avisan que hay una fractura evidente en la comunidad política, en palabras de López (2004):

La indignación y la desaprobación, al igual que el resentimiento, evidencian una limitación reactiva de buena voluntad hacia el agente que ha incumplido la demanda conscientemente y ha roto la dinámica de reciprocidad. A este agente se le sigue considerando miembro de la comunidad moral, pero un miembro en deuda con ella. (p. 40)

En síntesis, la defensa del resentimiento llevada a cabo por Smith no debe confundirse con una exaltación de las pasiones antisociales, como la ira o el deseo de venganza desproporcionado, por el contrario, el justo resentimiento demanda de la virtud del self-command y de la moderación, pues no puede hablarse de resentimiento apropiado sin un adecuado rebajamiento y restricción de las propias pasiones.

\section{A manera de conclusión: ¿ Perdonar lo imperdonable?}

EN LA PARTE VI de TMS Adam Smith relaciona de manera puntual la justa indignación con el resentimiento y el perdón. La cita que nos interesa es la siguiente:

El control (The command) de la ira es en muchas ocasiones no menos generoso y noble que el del miedo [...] Pero esta justa indignación no es más que ira contenida (restraint) y apropiadamente (properly) atenuada hasta el nivel en que puede ser asumida por el espectador imparcial. La pasión fanfarrona 
y estrepitosa que va más allá es siempre repugnante y ofensiva y hace que nos interesemos no en la persona enfadada sino con la persona con la que está enfadada. La nobleza del perdón parece en muchas ocasiones superior incluso a la más absoluta corrección (propriety) del enojo. Cuando se han presentado las excusas apropiadas a la parte ofendida o, incluso sin ellas, cuando el interés público requiere que los más mortales enemigos se unan para el cumplimiento de un deber importante, la persona que puede abandonar toda animosidad y actuar con confianza y cordialidad hacia quien la ha agraviado del modo más cruel parece merecer con justicia nuestra máxima admiración. (TMS VI.iii.9. p. 241)

Lo primero que quiero señalar es que en esta parte de la TMS Adam Smith enlaza las virtudes cardinales de la prudencia, la justicia y la benevolencia al "selfcommand", el cual confiere un "mayor brillo y lustre" a todas las demás virtudes. Esta cita ayuda a precisar una de las ideas propuestas al comienzo de este trabajo cuando señalaba que la virtud "self-command" es lo que permite moderar aquellas pasiones como el odio y la venganza las cuales, de acuerdo con Adam Smith son las que más "tienden a separar a las personas" (TMS VI.iii.16. p. 243).

En segundo lugar, pienso que la trasgresión de la ley marca un hito insoluble en el tiempo que altera las relaciones sociales entre el agresor y su víctima. Lo que acontece es la ruptura o el quiebre de los lazos de solidaridad entre los seres humanos, y por ende, el quebrantamiento del orden de la sociedad política. Restringir la ira implica redirigir la mirada hacia los motivos que tuvo el agresor para actuar de esa forma, lo cual exige pasar del punto de vista del agente al del espectador para realizar una evaluación reflexiva de la situación. Para ello se requiere del self-command: esta virtud es la que le permite al agente moderar su pasión hasta el punto de propiedad en que puede ser asumida por el espectador (Carrasco, 2014, p. 74).

El self-command es la virtud que permite al agente considerar sus sentimientos no como buenos o malos en sí mismos sino como apropiados o inapropiados al contexto social (Carrasco, 2004, p. 102). El espectador imparcial "no solo juzga las acciones y motivos del agente, sino que se convierte en interiorizado y juez de sus propios acciones y motivos. Por lo tanto, la originalidad del espectador imparcial de Smith es su capacidad para explicar el origen y la naturaleza de la conciencia” (Stevens, 2011, p. 8). Una conciencia que, en el caso de la víctima, puede considerarse como una conciencia ofendida o agraviada pero no por eso 
carente de capacidad de juicio y reflexividad. Conciencia magnánima en la medida en que perdonar implica instituir un nuevo corte en el tiempo que tiene por objetivo restablecer la simpatía con el victimario o, al menos, atenuar la antipatía y el deseo de venganza hasta un punto que podamos acompañar. Conciencia que, en el caso del victimario, puede considerarse como "mala conciencia" pues intencionalmente ocasionó un daño real y concreto en la víctima. Finalmente, pienso que el proceso de la simpatía permite superar el resentimiento pues este, en último término nos impele no solo a castigar sino también a perdonar. La víctima, con su capacidad de perdonar, puede pensarse no solo como sufriente sino, particularmente, y lo que es mucho más significativo, como sobreviviente en la restitución de su vida y copartícipe en la rehabilitación del victimario.

Crespo (2007) afirma: "al perdonar al malhechor, la víctima extiende una actitud de auténtica buena voluntad hacia el delincuente como persona. Sin embargo, aquel que perdona no extiende esta actitud de buena voluntad hacia la acción que realiza el delincuente. Podemos oponemos enérgicamente al mal comportamiento sin oponernos a los malhechores como personas" (p. 586). Lo que desaprueba cabalmente el espectador son tanto los motivos que tuvo el agente para actuar de esa manera como los efectos lesivos de la acción. El resentimiento desmedido rompe el proceso simpatético pero la justa indignación y el perdón impulsan a la víctima a moderar su antipatía hacia el agresor y a obrar con benevolencia. La víctima actúa de manera magnánima cuando está en capacidad de conceder el perdón a quien "ha presentado las excusas apropiadas a la parte ofendida”. No obstante, en algunas ocasiones, la persona injuriada puede experimentar la libertad y la fuerza necesaria para conceder el perdón gratuitamente.

Siguiendo a López (2013): "esto es muy importante en el caso colombiano, pues en diversas comunidades las víctimas se ven obligadas a convivir con sus victimarios, a compartir la vida cotidiana, muchas veces en medio del silencio y el temor" (p. 93). Perdonar es una experiencia deliberada e intencional que ayuda a rehacer las relaciones sociales e interpersonales entre el agresor y la víctima (Crespo, 2007, p. 586). El perdón se constituye en una experiencia sui generis capaz de restablecer la confianza entre los miembros de la comunidad política, pero también en una fuerza liberadora por la cual se logra una nueva interdependencia y solidaridad entre los sentimientos del agente (víctima) y los de cualquier miembro perteneciente a esta sociedad. Como afirma López (2013): 
es así como el resentimiento y la indignación pueden abrir el camino para el reconocimiento del delito y la confesión de la verdad por parte de los victimarios; pero, una sociedad incapaz de resentimiento y de indignación, no cuenta con las fuerzas suficientes para exigirlo a los perpetradores de crímenes atroces ni para exigir al Estado que haga justicia (p. 94).

Algunos autores, como es el caso de Murphy (1988), argumentan que el arrepentimiento es "la manera más clara en la que el malhechor puede romper de sí mismo, de su pasado equivocado. De hacer un cambio sincero de corazón, él se está retirando su apoyo desde su comportamiento inmoral pasado” (p. 24). Si bien es cierto que el arrepentimiento facilita este proceso de antipatía y desaprobación del agente respecto de su conducta pasada no considero que sea una condición para otorgar el perdón, pues la justa indignación puede impulsar a la víctima a concederlo aún sin que el victimario confiese o se arrepienta púbicamente de sus crímenes. En esto reside precisamente la fuerza resilente de la persona que ha sido injuriada, en su capacidad de conceder un perdón gratuito y libre capaz de rehacer la historia y de vehicular nuevas prácticas aportando a la construcción de un mundo más seguro y habitable. El perdón, como una acción total que inaugura un tiempo nuevo, rehabilita a la víctima para actuar libremente incluso cuando el victimario pueda resistirse a reconocer todo el daño causado. En esta misma línea López (2013) argumenta:

Más allá de lo que se espera de los victimarios, la historia colombiana muestra que muchas veces el camino del perdón debe ser emprendido por parte de las víctimas en ausencia del arrepentimiento de los victimarios y en medio de la impunidad. Si se condiciona el perdón al reconocimiento público de los crímenes por parte de los perpetradores y al castigo que debe ser aplicado, es posible que las comunidades y las personas que han sido víctimas de los grupos armados prolonguen su sufrimiento a causa del mal recibido, sin poderse reponer y sin abrirse a un futuro mejor. (p. 94)

El "perdón magnánimo" impulsa a la víctima a asumir una actitud benevolente, primero, con el agresor, quien por esa misma acción queda enaltecido en su ser social y personal, y, segundo, con la propia "mismidad", pues la víctima al rebajar su amor propio y contener su deseo de retaliación también es benevolente consigo misma. Sin embargo, el perdón no puede significar olvidar el sufrimiento y hacer tabla rasa sobre lo acaecido. Por el contrario, "perdón, para que 
valga la pena y pueda ser por tanto de lo imperdonable, ya que lo perdonable será perdonado sin problemas por alguna compensación como castigo o reparación, no puede significar olvido; todo lo contrario, exige que haya a quién y qué perdonar" (Hoyos, 20017, p. 1). Y para incitar un nuevo comienzo me pregunto: “'Acaso no hay que mantener que un perdón digno de ese nombre, si es que alguna vez se da, debe perdonar lo imperdonable, y ello sin ninguna condición?” (Derrida, 2008, p. 123).

\section{Referencias}

Brooks, T. (2012). Punishment and Moral sentiments. The Modern Law Review, 66(2), pp. 281-293. doi: 10.1080/0305724840130202

Carrasco, M. (2004). Adam Smith's Reconstruction of Practical Reason. The Review of Metaphysics, 58, pp. 81-116. Recuperado de http://www.jstor.org/ stable/20130424

Carrasco, M. A. (2014). Reinterpretación del espectador imparcial: impersonalidad utilitarista o respeto a la dignidad. Crítica: Revista Hispanoamericana de Filosofía, 46(137), pp. 61-84.

Comins-Mingol, I. (2015). De víctimas a sobrevivientes: la fuerza poiética y resiliente del cuidar. Convergencia, 67, pp. 35-54.

Crespo, M. (2007). Forgiveness and its Healing Effects in the Face of Suffering and Death. American Catholic Philosophical Quarterly, 81(4), pp. 579-594.

Darwall, S. (1999). Sympathetic Liberalism: Recent Work on Adam Smith. Philosophy \& Public Affairs, 28(2), pp. 139-164.

Derrida, J. (2008). El Perdón. En: J. A. Z. Medina, R. Mate, J. Mayorga \& M. Rubio (Ed.), El Perdón, Virtud Politica (1ª ed.). Barcelona: Antropos.

Fassin, D. (2013). On Resentment and Ressentiment The Politics and Ethics of Moral Emotions Author(s): Didier Fassin Source: Current On Resentment and Ressentiment The Politics and Ethics of Moral Emotions. Anthropology Current Anthropology, 54(3), pp. 249-267. doi: 10.1086/670390

Fleischacker, S. (2006). Adam Smith y la Igualdad. Estudios Públicos, 104, pp. 25-50. 
Frankfurt, H. (1997). Equality and Respect. Social Research, 64(1), pp. 3-15. Recuperado de http://www.jstor.org/stable/40971156

Fricke, C. (2015). Lo que no podemos hacernos el uno al otro. Sobre el perdón y la vulnerabilidad moral. Universitas Philosophica, 64(32), pp. 125-151. doi: 10.11144/Javeriana.uph32-64.uopv

Fricke, K. (2011). Adam Smith and "the Most Sacred Rules of Justice." The Adam Smith Review, VI, pp. 46-74.

Hoyos, G. (2007). Las victimas frente a la búsqueda de la verdad y la reparación en Colombia. Bogotá: Editorial Pontificia Universidad Javeriana.

Gutiérrez, G. (1998). Etica y economía en Adam Smith y Friedrich Hayek. (Coleccion Sophia, Ed.) (1 $1^{\mathrm{a}}$ ed.). México: Editorial Universidad Iberoamericana.

López, E. A. (2013). Perdonar sí, olvidar no: una aproximación a la reconciliación en Colombia desde los sentimientos morales. Universitas Philosophica, 61(30), pp. 85-96.

Minow, M. \& Crocker, D. M. R. (2011). Justicia transicional. Bogotá: Siglo del Hombre.

Murphy, G. (1988). Forgiveness and Mercy. Cambridge: University Press.

Nanay, B. (2010). Adam Smith's Concept of Sympathy and its Contemporary Interpretations. Adam Smith Review, 5, pp. 85-105.

Prada Londoño, M. (2010). Sobre el perdón: una reflexión desde Paul Ricour. Miradas sobre la reconciliación: reflexiones y experiencias. Bogotá: Ediciones Unisalle

Smith, A. (1982). The Theory of Moral Sentiments. Indianapolis: Liberty Fund. Stalley, R. (2012). Adam Smith and the Theory of Punishment. Journal of Scottish Philosophy, 10(1), pp. 69-89. Recuperado de http://philpapers.org/rec/ STAASA-4.

Stevens, D. E. (2011). Rediscovering Adam Smith. How The Theory of Moral Sentiments can explain emerging evidence in experimental economics. Working Papers Nro. 04. Glasgow: Adam Smith Research Foundation. Recuperado de http://www.gla.ac.uk/media/media_215455_en.pdf 